\title{
SEVERE VARUS AND VALGUS DEFORMITIES TREATED BY TOTAL KNEE ARTHROPLASTY
}

\author{
Th. KARACHALIOS, P. P. SARANGI, J. H. NEWMAN
}

From Winford Orthopaedic Hospital, Bristol, England

We report a prospective case-controlled study which compared the outcome of knee replacement in seriously deformed and slightly deformed knees. There were 51 knees with varus or valgus deformity greater than $20^{\circ}$ matched for age, gender, disease, type of prosthesis and time of operation with a control group in which the alignment of the leg was within $5^{\circ}$ of normal.

The clinical outcome at a mean 5.5 years was similar in the two groups. Some deformity persisted in 14 patients in the first group, 13 of whom were initially in valgus. These patients had a significantly poorer mean clinical outcome. Lateral dislocation or subluxation of the patella was found in four knees, all of which had had valgus deformity of $30^{\circ}$ or more.

J Bone Joint Surg [Br] 1994; 76-B:938-42.

Received 10 November 1993; Accepted after revision 13 April 1994

Restoration of the normal mechanical axis of the knee and balancing of the surrounding soft tissues have been shown to have an important bearing on the final outcome of knee replacement operations (Tew and Waugh 1985; Krackow and Holtgrewe 1990). In severely deformed knees, whether varus or valgus, these goals may be difficult to achieve.

We report the results of total knee arthroplasty in a group of severely deformed knees.

\section{PATIENTS AND METHODS}

Between June 1981 and July 1990, 51 total knee replacements were performed on knees with varus or valgus angulation of more than $20^{\circ}$ (50 patients; group $\mathrm{A}$, Fig. 1). In all the replacements a cemented Kinematic-1 prosthesis (Howmedica, Rutherford, New Jersey) was

Th. Karachalios, MD, Orthopaedic Surgeon

P. P. Sarangi, FRCS, Senior Orthopaedic Registrar

J. H. Newman, FRCS, Consultant Orthopaedic Surgeon

Winford Orthopaedic Hospital, Winford, Bristol BS18 8AG, UK.

Correspondence should be sent to Dr Th. Karachalios at the Orthopaedic Department, KAT Hospital, Kiffisia, Athens 14561, Greece.

(C)1994 British Editorial Society of Bone and Joint Surgery $0301-620 X / 94 / 6868 \$ 2.00$ used. This is a minimally-constrained posterior-cruciateretaining prosthesis with an anatomical femoral component, metal-backed tibial tray and an all-plastic symmetrical patellar component.

A second group of patients (group B) individually matched for age, gender, type of arthritis, type of prosthesis and date of operation (to within one month) was randomly selected to act as a control group (Table I).

Table I. Details and diagnoses, by number and percentage of the deformed (group A) and undeformed (group B) knees

\begin{tabular}{lll}
\hline & $\begin{array}{l}\text { Group A } \\
(\mathbf{n}=\mathbf{5 1})\end{array}$ & $\begin{array}{l}\text { Group B } \\
(\mathbf{n}=\mathbf{5 1})\end{array}$ \\
\hline Age (yr) & 78.3 & 78.3 \\
Male: female & $10: 41$ & $10: 41$ \\
Right: left & $26: 25$ & $24: 27$ \\
Severe valgus (group A1) & 34 & \\
Severe varus (group A2) & 17 & \\
& & \\
Diagnosis & & \\
$\quad \begin{array}{l}\text { Osteoarthritis } \\
\text { Rheumatoid arthritis }\end{array}$ & $31(60.8)$ & $33(64.7)$ \\
$\quad$ Post-traumatic & $16(31.4)$ & $16(31.4)$ \\
$\quad$ Avascular necrosis & $3(5.9)$ & $2(3.9)$ \\
\hline
\end{tabular}

All patients in this group had angular deformities of less than $5^{\circ}$ from the anatomical normal of $5^{\circ}$ to $7^{\circ}$ valgus.

The preoperative diagnoses in the two groups are given in Table I. In group A, of the 31 patients with osteoarthritis, 19 had valgus knees and 12 had varus knees; of the 16 patients with rheumatoid arthritis, 12 had valgus and 4 varus knees.

Clinical evaluation was performed using the Bristol Knee Score preoperatively and at 8 months, 2 years, 5 years and 10 years postoperatively. This is a 100 points scoring system: 40 points are for pain, 27 for function, 20 for movement, 10 for deformity and 3 for laxity in extension. Radiographs, taken at the same time, included anteroposterior standing radiographs of the whole lower limb and tangential patellofemoral views.

The above data were collected prospectively as part of a knee survey in Bristol. In addition, all patients were recalled for final clinical assessment by the authors and radiography was repeated at that time. 

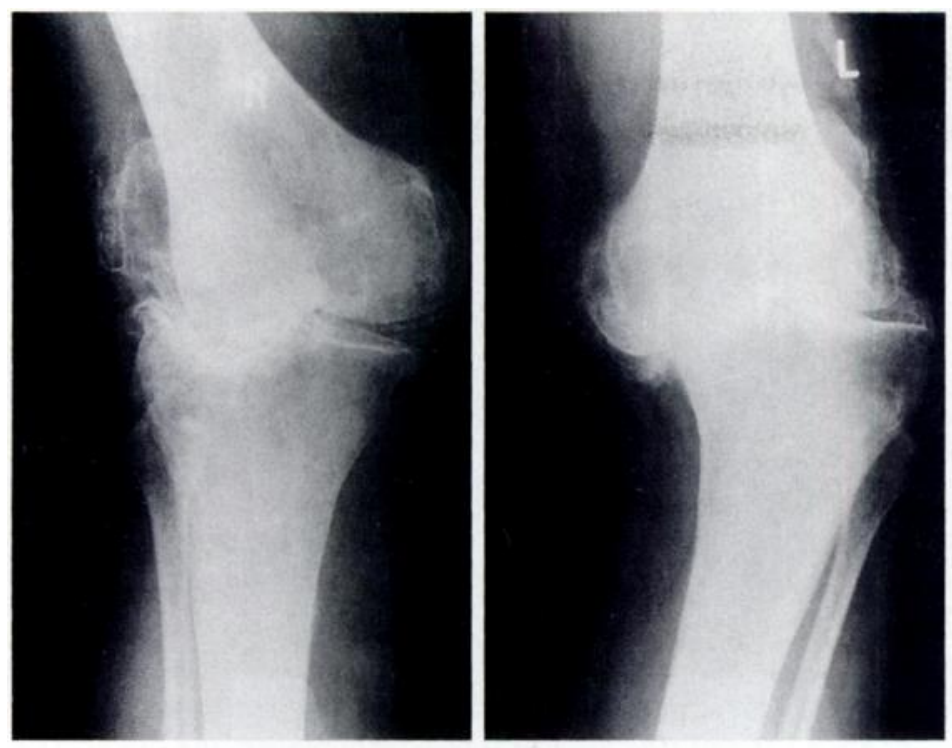

Fig. 1a
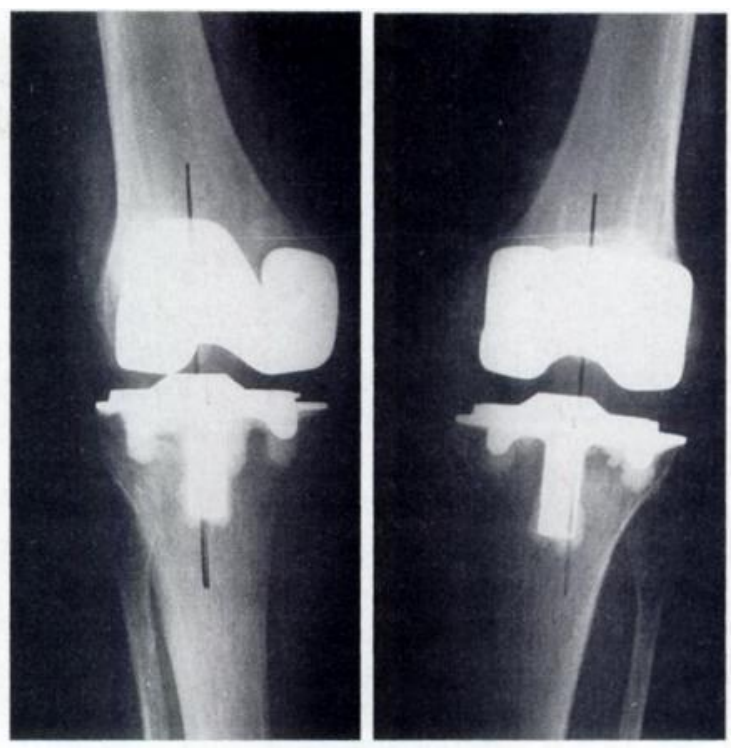

Fig. lb

Radiographs of severely deformed knees (a) preoperatively (right, $30^{\circ}$ valgus; left, $20^{\circ}$ varus) and (b) postoperatively with correction of the deformities (right, $3^{\circ}$ valgus; left, $2^{\circ}$ valgus).

Radiographic measurements. Knee alignment was recorded as the tibiofemoral angle which is the angle formed at the knee by the intersection of the longitudinal axes of the femoral and tibial shafts. The displacement (either medial or lateral) of the mechanical axis of the limb from the centre of the tibial plateau was measured. Patellar subluxation or dislocation was noted on the tangential patellofemoral views.

Lucent lines and their progression were recorded using the Knee Society's radiographic evaluation system (Ewald 1989).

\section{RESULTS}

The mean follow-up for both groups was 5.5 years ( 2 to 11). Both groups showed significant improvements ( $\mathrm{p}=0.001$, paired $t$-test $\mathrm{p}<0.001$, paired Wilcoxon test $)$ in their knee assessment scores as a result of surgery (Table II); $84 \%$ of group A and $92 \%$ of group B obtained good or excellent results. There was no deterioration in the knee scores over the follow-up period. Although there was no statistical difference between the mean knee scores of the two groups at final review there were twice as many unsatisfactory results in group $A(p=0.10$, paired $t$-test; $\mathrm{p}=0.159$ paired Wilcoxon test). Further analysis of the group-A knees showed that those with preoperative valgus deformities (A1) did as well as those with initial varus deformities (A2) (no statistically significant difference, $\mathrm{p}=0.96$, unpaired $t$-test).

In group A 14 knees (27.4\%) and in group B six knees $(11.8 \%)$ had postoperative alignment outside the normal range of $5^{\circ}$ to $7^{\circ}$ valgus. Most of these malalignments were minor, within the range $0^{\circ}$ to $15^{\circ}$ valgus. A tibiofemoral angle outside this range was found in five

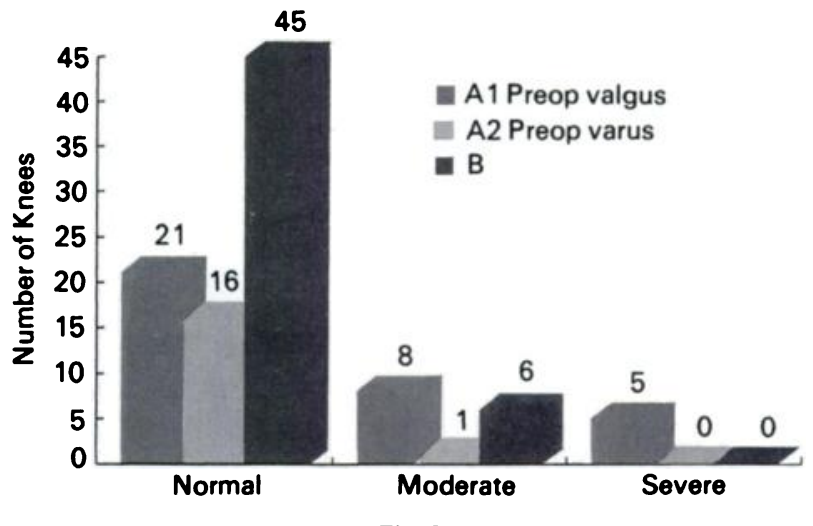

Postoperative knee alignment in groups A1, A2 and B (normal, $5^{\circ}$ to $7^{\circ}$ valgus; moderate malalignment, outside normal range but within $0^{\circ}$ to $15^{\circ}$ valgus; severe malalignment, outside $0^{\circ}$ to $15^{\circ}$ valgus).

knees in group A (Fig. 2). Thirteen of the 14 knees in group $\mathrm{A}$ in which anatomical alignment was not restored had initial valgus deformities. These patients with residual deformity had a significantly worse clinical result (average score 74.8$)$ than did those in group B $(p<0.01>0.001$, unpaired $t$-test).

Preoperative clinical examination showed severe medial or lateral laxity (more than $15^{\circ}$ in either direction) of the extended knee in 15 cases (29.4\%) in group A and in three $(5.9 \%)$ in group B (Fig. 3a). At final review ten $(19.6 \%)$ knees in group A and five $(9.8 \%)$ in group B had persistent moderate laxity (between $5^{\circ}$ and $15^{\circ}$ in either direction) (Fig. 3b). Only one patient in group A had persistent severe laxity. Patients with moderate residual laxity did no worse than those with no laxity. The patient 


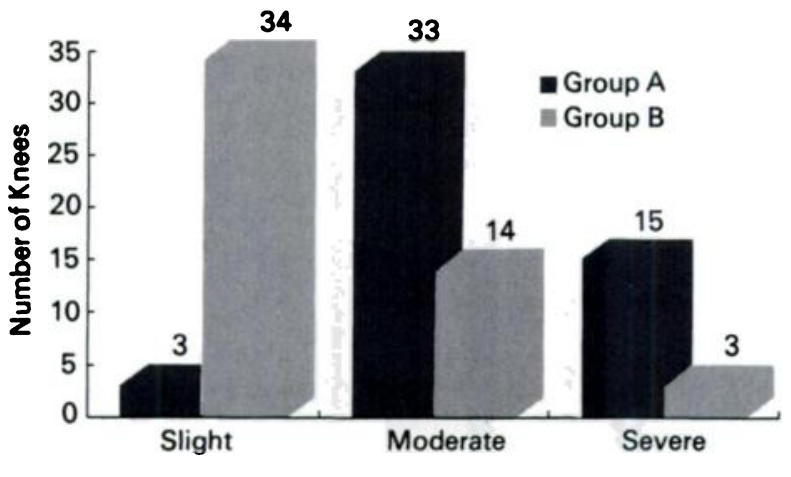

Fig. 3a

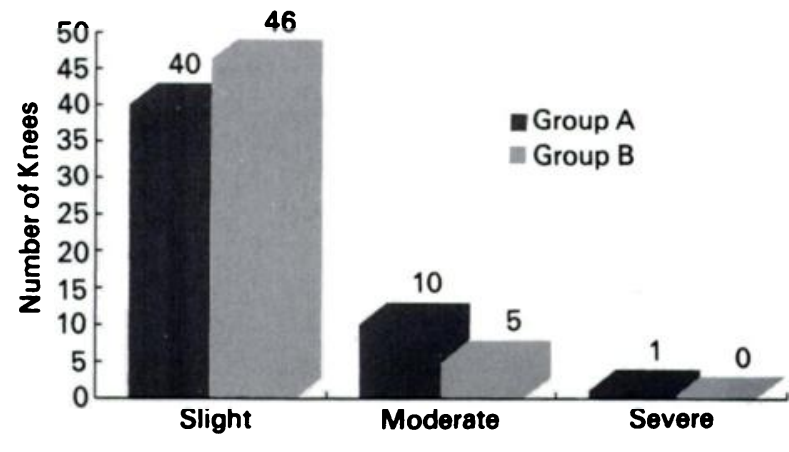

Fig. 3b

Laxity in extension (a) preoperatively and (b) postoperatively, for knees in groups $\mathrm{A}$ and $\mathrm{B}$ (slight laxity, $0^{\circ}$ to $5^{\circ} ;$ moderate, $6^{\circ}$ to $15^{\circ} ;$ severe, $>16^{\circ}$ ).

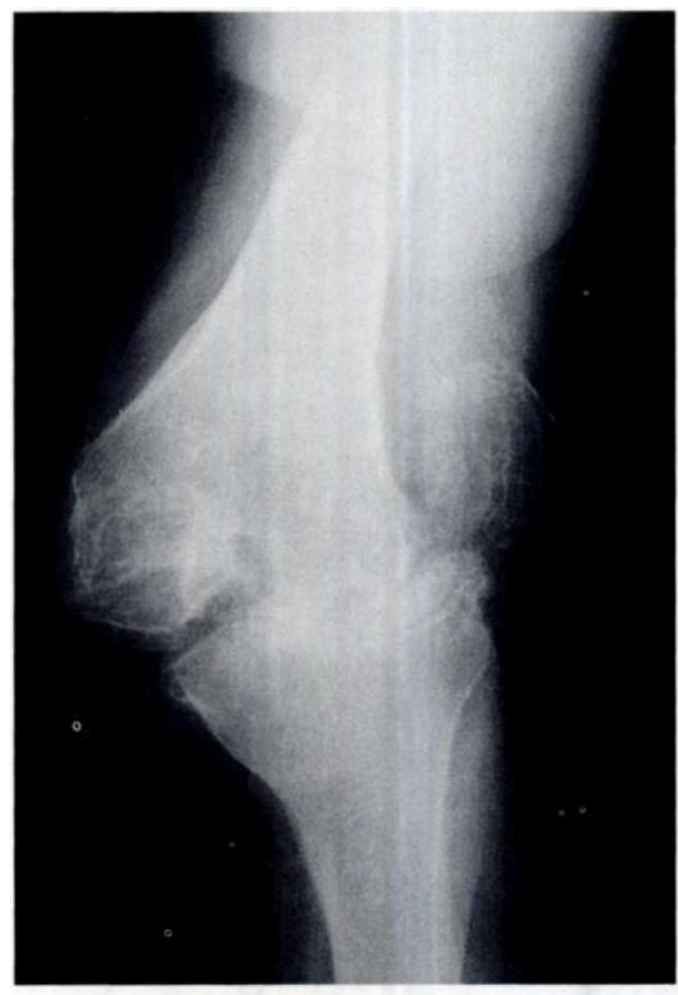

Fig. 4a

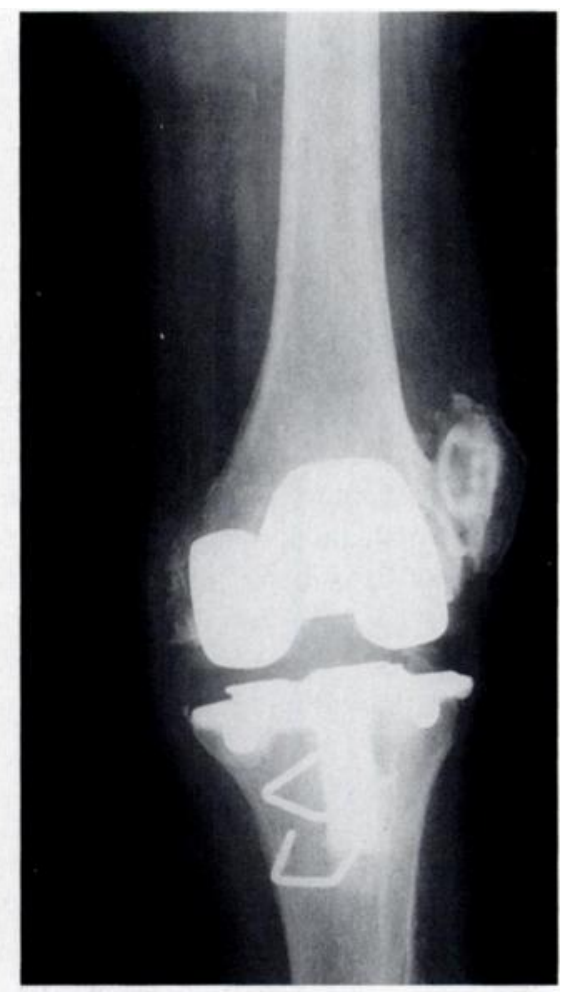

Fig. 4b

Radiographs showing a knee with $40^{\circ}$ valgus deformity (a) preoperatively and (b) postoperatively corrected to $3^{\circ}$ valgus but with dislocation of the patella.

with the severe residual laxity obtained a poor result, perhaps because she also had a persistent valgus deformity.

Eight patients in group $\mathbf{A}$ had a fair or poor clinical result; in three this was due to the poor general health of the patient, in one to severe persistent valgus deformity and ligamentous laxity and in one to patellar dislocation (Fig. 4). The other three patients all had extensor mechanism malalignment and lateral subluxation of the patella. All the patients with extensor mechanism malalignment had had a preoperative valgus deformity of more than $30^{\circ}$. The fair and poor results in group-B patients were mainly attributable to poor general health.
Radiographic results. In group $A$ the average preoperative tibiofemoral angle was $27^{\circ}$ (range 20 to 40 ) in valgus knees and $24^{\circ}$ (range 20 to 30 ) in the varus knees. At review the average angle was $9.2^{\circ}$ valgus (range 3 to 20) for preoperative valgus knees and $6^{\circ}$ valgus (range 5 varus to 8 valgus) for preoperative varus knees.

In both groups, non-progressive radiolucent lines of $1 \mathrm{~mm}$ or less were found around $36 \%$ of the tibial components on the anteroposterior projections, mainly in zones 1 and 4 . No lucent lines were found around the stems of the tibial components (zones 5, 6 and 7). Only in one knee in group $B$ was there a progressive radiolucent 


\begin{tabular}{lll}
$\begin{array}{l}\text { Table II. Results of surgery and knee scores by number and percentage in group-A } \\
\text { and group-B knees (group A1 denotes preoperative valgus and group A2 preoperative } \\
\text { varus) }\end{array}$ & Group A & Group B \\
\hline Knee score & $23(45.1)$ & $26(51.0)$ \\
\hline Excellent (85 to 100 points) & $20(39.2)$ & $21(41.1)$ \\
Good (70 to 84 points) & $5(9.8)$ & $3(5.9)$ \\
Fair (60 to 69 points) & $3(5.9)$ & $1(2.0)$ \\
Poor (< 60 points) & $45.3(10.6 ; 23$ to 73) & $48.3(12.9 ; 31$ to 71$)$ \\
Mean preoperative score (SD; range) & $81.04(14.2 ; 30$ to 97) & $84.5(11.1 ; 57$ to 100$)$ \\
Mean postoperative score (SD; range) \\
$\begin{array}{l}\text { Group A1 (SD) } \\
\text { Group A2 (SD) }\end{array}$ & $80.88(12.1)$ \\
\hline
\end{tabular}

line (tibial component). On the lateral projections $28 \%$ of the femoral components showed non-progressive radiolucent lines of less than $1 \mathrm{~mm}$ and these were found predominantly in zones 1,2 and 4 . No radiolucent lines were found around the stems of the components (zones 5, 6 and 7)

No significant difference was found between the two groups when radiolucent lines were compared, nor was there any significant difference in the number of lucent lines in those patients left undercorrected and those with normal alignment.

\section{DISCUSSION}

Early types of total knee replacement corrected deformity and controlled soft-tissue laxity by the inherent stability of the implant. These designs have been replaced by less constrained condylar designs that rely on soft-tissue balance to achieve and maintain alignment and excellent results have been reported (Ranawat and Boachie-Adjei 1988). The few series of operations performed for grossly deformed knees that have been reported, however, had less satisfactory results (Krackow et al 1991; Stern, Moeckel and Insall 1991).

Our comparative study showed that the average clinical results obtained in grossly deformed knees were as good as those in undeformed knees but that there were more problems of undercorrection of the deformity and patellofemoral malalignment.

Ewald et al (1984) and Teeny et al (1991) suggested that preoperative varus deformities tended to be in mild varus postoperatively but this was not our experience. Satisfactory correction was obtained by radical release of the medial ligament and the pes anserinus when necessary.

Full correction of the severe valgus deformities, however, was obtained in only $75 \%$ of cases. Stern et al (1991) reporting a series of 134 knee replacements with $10^{\circ}$ or greater valgus deformity, also observed that only $76 \%$ were fully corrected at surgery. Both series clearly show that full correction can be achieved but the fact that $25 \%$ of cases have residual deformity suggests that great efforts have to be made to ensure full correction. This may mean release of the fascia lata, the lateral ligament, the posterolateral capsule, the popliteus tendon and possibly lengthening of biceps tendon. Krackow et al (1991) reported $90 \%$ good results when correcting moderate valgus knees using a posterior-cruciateligament-sparing prosthesis. The wisdom of striving to preserve this ligament in the face of gross deformity is questioned and perhaps full correction would have been achieved more often if it had been divided.

Residual valgus deformity did not result in early component failure but was associated with a poorer clinical outcome. It was also associated with problems of patellofemoral alignment which impaired the overall clinical result. We think that patellofemoral malalignment was due to inadequate release of the lateral soft tissues when correcting the valgus deformity and not to malrotation of the prosthetic components.

Postoperative instability is a possible problem when using an unconstrained condylar type of implant for a grossly deformed knee. Satisfactory stability was, however, obtained in all but one of our cases despite the extensive nature of the soft-tissue releases performed for the grossly deformed knees. A moderate degree of instability in extension was not uncommon but did not significantly affect the clinical outcome. Krackow et al (1991) have previously shown that slight laxity does not usually impair the clinical result and Edwards, Millar and Chan (1989) have shown that a degree of ligamentous laxity is desirable.

Conclusions. A condylar type of knee replacement can give good overall results in severely deformed knees, but not so consistently as in slightly deformed joints. It may be desirable therefore to operate before major deformity occurs. Loss of stability is not usually a problem even after extensive soft-tissue release, but failure to obtain full correction of a valgus deformity can result in patellar tracking problems and a poor clinical result.

No benefits in any form have been received or will be received from a commercial party related directly or indirectly to the subject of this article. 


\section{REFERENCES}

Edwards E, Millar J, Chan C. An assessment of the effect of collateral ligament instability on results following total knee replacements. $J$ Bone Joint Surg [Br] 1989; 71-B:338-9.

Ewald FC. The knee society total knee arthroplasty roentgenographic evaluation and scoring system. Clin Orthop 1989; 248:9-12.

Ewald FC, Jacobs MA, Miegel RE, et al. Kinematic total knee replacement. J Bone Joint Surg [Am] 1984; 66-A:1032-40.

Krackow KA, Holtgrewe JL. Experience with a new technique for managing severely overcorrected valgus high tibial osteotomy at total knee arthroplasty. Clin Orthop 1990; 258:213-24.
Krackow KA, Jones MM, Teeny SM, Hungerford DS. Primary total knee arthroplasty in patients with fixed valgus deformity. Clin Orthop $1991 ; 273: 9-18$.

Ranawat CS, Boachie-Adjei O. Survivorship analysis and results of total condylar knee arthroplasty: 8-11 year follow-up period. Clin Orthop 1988; 226:6-13.

Stern SH, Moeckel BH, Insall JN. Total knee arthroplasty in valgus knees. Clin Orthop 1991; 273:5-8.

Teeny SM, Krackow KA, Hungerford DS, Jones M. Primary total knee arthroplasty in patients with deformity: a comparative study. Clin Orthop 1991; 273:19-31.

Tew M, Waugh W. Tibiofemoral alignment and the results of knee replacement. J Bone Joint Surg [Br] 1985; 67-B:551-6. 